\title{
LÍQUIDO CEFALORRAQUIDIANO NO DIAGNÓSTICO DA ESQUISTOSSOMOSE RAQUIMEDULAR
}

\author{
Egídio Tesser ${ }^{1}$, Maria de Lourdes Amud Ali dos Reis², Primavera Borelli, \\ Sandro Luiz de Andrade Matas ${ }^{4}$, João Baptista dos Reis Filho ${ }^{5}$
}

\begin{abstract}
RESUMO - As três espécies de esquistossoma podem comprometer o sistema nervoso. O S. mansoni é responsável pela esquistossomose no Brasil, sendo a mielopatia uma forma grave desta helmintose. 0 p ropósito deste trabalho é analisar as alterações do líquido cefalorraquidiano (LCR) para dar mais subsídios para o diagnóstico da esquistossomose raquimedular. Fizeram parte deste estudo 22 amostras de LCR de pacientes com esquistossomose espinal. Os resultados das análises destas amostras mostraram que a associação de alterações do LCR com quadro inflamatório e RIFI-IgM positiva ocorreu em $88 \%$ dos pacientes, que o eosinófilo esteve presente em apenas 7 amostras (36,8\%), e que 3 dos 22 pacientes estudados a p resentaram LCR normal. Conclui-se que o exame de LCR é coadjuvante muito útil para o diagnóstico da neuroesquistossomose.
\end{abstract}

PALAVRAS-CHAVE: líquido cefalorraquidiano, esquistossomose raquimedular.

\begin{abstract}
Cerebrospinal fluid in the diagnosis of spinal schistosomiasis
ABSTRACT - Cereb rospinal fluid (CSF) changes in spinal shistosomiasis have been described. Its characteristic features are mild to moderate pleocytosis, presence of eosinophils, slight to moderate protein increase, elevated gamma globulin concentration and a positive immune assay. Nevertheless, these abnomalities are not always present together and therefore difficulties may arise in the assessment of the diagnosis. The purpose of this paper is to evaluate the importance of each CSF alteration concerning the diagnosis in 22 cases of spinal shistosomiasis. According to the results, only $20 \%$ of the cases had all the five feature that are considered to be characteristic of spinal shistomiasis. Abnormal cell count was present in $86 \%$, p rotein increase in $77.3 \%$, immunoglobulin $\mathrm{G}$ increase in $60,8 \%$, eosinophils were present in $36.8 \%$ and indirect fluorescent antibody test was positive in $68.2 \%$. In three cases all CSF parameters studied were within the normal limits. As the most specific test among those described was the indirect fluorescent antibody test, it should be regarded for the diagnosis.
\end{abstract}

KEY WORDS: cerebrospinal fluid, spinal schistosomiasis.

A neuroesquistossomose tem sido considerada doença rara. No entanto, com a otimização da metodologia diagnóstica, número cada vez maior de casos vem sendo diagnosticado ${ }^{1-3}$. A apresentação neurológica da neuroesquistossomose é variável e não existe uma manifestação típica para orientar o diagnóstico'; a apresentação clássica da patologia é de dor lombar baixa4.

A mielopatia é uma forma grave dessa helmintose e o prognóstico depende do diagnóstico precoce $^{5}$. A comprovação histológica nessa situação, é trabalhosa e arriscada, pois para tanto há necessidade de procedimento cirúrgico para se obter um fragmento de meninge, de raiz nervosa ou de medula espinhal. Até o presente momento, o diagnóstico da esquistossomose medular é de probabilidade. Considerando que o tratamento precoce dessa doença é fundamental para se evitar seqüelas e que o uso indiscriminado do praziquantel pode trazer conseqüências sérias para pacientes com outras patologias medulares, é necessário um diagnóstico seguroantes de se introduzir este medicamento ${ }^{6}$.

O propósito deste trabalho é analisar as alterações do líquido cefalorraquidiano (LCR) para dar mais subsídios para o diagnóstico da esquistossomose raquimedular.

Disciplina de Neurologia da Universidade Federal de São Paulo (UNIFESP) São Paulo SP, Brasil, Curso de Pós-graduação em Análises Clínicas da Faculdade de Ciências Farmacêuticas da Universidade de São Paulo (USP) e Universidade Estadual de Londrina, Paraná

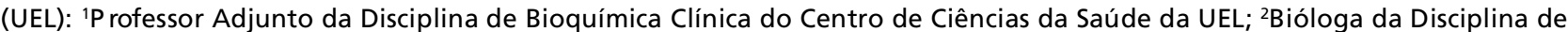
Neurologia da UNIFESP; ${ }^{3} \mathrm{P}$ rofa $\mathrm{Dr}^{\mathrm{a}}$ da Disciplina de Hematologia do Departamento de Análises Clínicas da Faculdade de Ciências Farmacêuticas da USP; ${ }^{4}$ Médico da Disciplina de Neurologia de UNIFESP; ${ }^{5}$ Prof. Adjunto da Disciplina de Neurologia da UNIFESP.

Recebido 4 Agosto 2004, recebido na forma final 13 Janeiro 2005. Aceito 21 Março 2005.

Dr. Egídio Tesser - R. Pio XII 731 / 1302 - 86020-381 Londrina PR - Brasil. E-mail: egidiotesser@yahoo.com.br 


\section{MÉTODO}

Fazem parte deste trabalho 22 amostras de LCR, obtidas por punção lombar de 22 pacientes com diagnóstico de neuroesquistossomose. A idade destes pacientes variou de 5 a 37 anos, sendo 15 do sexo masculino. As amostras foram selecionadas de pacientes atendidos no Hospital São Paulo da UNIFESP, com quadro neurológico de mielopatia compatível com neuroesquistossomose, tendo sido excluídos os pacientes com outras causas de mielopatias. Este estudo abrangeu pacientes atendidos no período de novembro de 1986 a outubro de 1995.

Os critérios de inclusão dos pacientes com neuroesquistossomose foram: quadro neurológico de mielomeningorradiculopatia compatível com neuroesquistossomose, caracterizado por paraplegia ou paralisia crural, podendo ser acompanhado de alterações das funções esfincteriana, vesical e retal, alterações da sensibilidade em membros inferiores e superiores, ou ambos, e disfunção erétil no grupo masculino; infecção sistêmica pelo Schistosoma mansonicomprovada pelo exame parasitológico de fezes ou biópsia de válvula retal; reação de imunofluorescência indireta (IFI) no soro, positiva para esquistossomose, utilizando-se lâminas de verme adulto parafinado como antígeno; reações imunoenzimática (ELISA), imunofluorescência indireta e fixação de complemento negativa para cisticerco de Taenia solium no LCR e soro; reação negativa para HTLV-1 pelo método ELISA no LCR e no soro.

As análises realizadas nas amostras de LCR foram: aspecto e cor; citologia, bioquímica, reações coloidais, reação de imunofluorescência indireta - IgM, utilizandose vermes adultos parafinados (RIFI-IgM). Em relação à IgG, a mesma foi determinada pelo método da imuno difusão radial em 20 das 22 amostras, considerado-se não haver alteração qualitativa das proteínas quando em proporção menor ou igual a $12 \%$ da proteína total.

As análises do VDRL, e hemaglutinação indireta para sífilis, a reação de ELISA, IFI e fixação do complemento (FC) para cisticercose, IF para toxoplasmose, tinta da China, exame bacterioscópico (Gram e Ziehl-Neelsen), cultura para bactérias e fungos apresentaram resultados negativos.

O padrão de normalidade do LCR utilizado nesta pesquisa foi baseado em Reis et al. ${ }^{7}$.

Este trabalho foi aprovado pelo Comitê de Ética da UNIFESP, do Centro de Ciências da Saúde da UEL e da Faculdade de Ciências Farmacêuticas da USP.

\section{RESULTADOS}

Alteração do LCR na neuroesquistossomose Das 22 amostras de LCR, 19 (86,3\%) apresentaram pelo menos uma alteração, enquanto que apenas 3 estiveram dentro do padrão de normalidade.

O número global de células esteve aumentado em 19 amostras (86,3\%). Nas amostras com pleiocitose, o número global de células variou 12,0 a $850 / \mathrm{mm}^{3}$.
Nas amostras com pleiocitose, o estudo citomorfológico mostrou que as células linfocitárias ocorreram na proporção de 76 a $98 \%$ e as células monocitárias na proporção de 2 a $22 \%$. As células plasmocitárias foram observadas em 8 amostras $(42,1 \%)$, em percentagem que variou de 1 a $8 \%$. Os granulócitos eosinófilos foram observados em 7 amostras (36,8\%), com percentagem que variou de 1 a $14 \%$. Percentagens iguais ou superiores a $2 \%$ foram encontradas em 5 amostras (22,7\%). Os neutrófilos se apresentaram em 3 amostras (15,8\%) e variaram de 1 a $6 \%$. Os granulócitos basófilos apareceram em apenas 1 amostra (5,3\%), em perc e ntagem de $1 \%$.

A taxa de proteínas totais variou de 17 a 280 mg/dL, estando aumentada em 17 (77,3\%) das 22 amostras.

A taxa de glicose variou de 47 a $96 \mathrm{mg} / \mathrm{dL} ; 14$ amostras $(63,6 \%)$ estiveram dentro da normalidade, enquanto que $8(36,4 \%)$ estiveram aumentadas.

A taxa de imunoglobulinas $G$ dosada em 20 amostras variou de 4,2 a 96,7 mg/dl; em relação à p roteína total variou de 3,7 a $60,8 \%$. Esteve acima de $12 \%$ em 14 amostras (70\%) e igual ou menor a $12 \%$ em 6 amostras (30\%).

A RIFI-IgM para esquistossomose no LCR, utilizando como antígeno verme adulto parafinado, esteve positiva em 15 amostras $(68,2 \%)$ e negativa em 7 (31,8\%).

Associação de alterações do LCR na neuroes quistossomose - O quadro inflamatório (associação do aumento no número global de células e aumento da taxa de proteínas) esteve presente em 17 amostras (77,3\%). Apenas em 2 amostras (9,0\%) ocorreu hipercitose sem aumento da proteína total.

A associação entre hipercitose e RIFI-IgM ocorreu em 15 amostras $(68,2 \%)$ e 7 amostras (31,8\%) não apresentaram tal associação.

A associação entre a hipercitose e alteração qualitativa das proteínas ocorreu em 13 amostras $(65 \%)$, enquanto que a ausência de associação ocorreu em 7 amostras (35\%).

A associação entre as alterações hipercitose, alteração qualitativa das proteínas e RIFI-IgM positiva ocorreu em 10 amostras (50\%); a ausência de associação também ocorreu em 10 amostras (50\%).

A associação entre as alterações hipercitose, p resença do eosinófilo, RIFI-IgM positiva foi de 6 amostras (27,3\%), enquanto que as ausências de associação foi de 16 amostras (72,7\%). 
A associação de hipercitose, alteração qualitativa das proteínas e presença do eosinófilo ocorreu em 5 amostras (25\%), enquanto que em 15 amostras (75\%) não houve essa associação.

Verificou-se que houve associação de hipercitose, presença do eosinófilo, alteração qualitativa das proteínas e reação de imunofluorescência indireta positiva (RIFI-IgM) somente em 4 amostras (20\%). Em 16 amostras (80\%) não houve essa associação de alterações.

A associação entre a alteração qualitativa de proteína, RIFI-IgM e presença do eosinófilos esteve presente em 4 amostras (20\%) e ausente em 16 amostras (80\%).

\section{DISCUSSÃO}

Com relação às alterações do LCR, verificou-se que em $86,3 \%$ dos pacientes o LCR esteve alterado, sendo a mais freqüente a hipercitose, que ocorre $u$ em 19 pacientes. Esses resultados são semelhantes aos citados por outros autores que encontraram pleiocitose variando de 81 a $95,3 \% \%^{5,8,9}$. A pleocitose pode ser encontrada em todas as amostras estudadas de LCR com neuroesquistossomose, sendo, porém inespecífica; está presente em qualquer processo inflamatório do sistema nervoso.

A RIFI-IgM para neuroesquistossomose foi positiva em 15 pacientes $(68,2 \%)$. Esta reação altamente específica $(90,8 \%)$, utiliza como antígeno corte parafinado de verme adulto, sendo portanto, uma p rova fundamental para o diagnóstico da verm inose. Estudos iniciais das propriedades antigênicas do Schistosoma mansoni $i^{10}$ propiciaram a pesquisa destes antígenos com aplicação no LCR $^{6}$ utilizando a técnica de cortes congelados e parafinados tanto do verme, como do ovo, comparando os resultados da reação. Neste estudo verificou-se que a RIFIIgM com cortes congelados era mais sensível do que a RIFI-IgM com cortes parafinados. Porém, em relação à especificidade, verificou-se que a RIFIIgM em cortes parafinados era específica para a esquistossomose raquimedular, enquanto que a RIFI-IgM em cortes congelados era positiva para pacientes esquistossomóticos, mesmo sem sinais ou sintomas da esquistossomose raquimedular.

Os antígenos de natureza glicoprotéica (termolábeis), distribuídos em todo o tegmento do verme, para os quais são dirigidas as imunoglobulinas, são prese nados pela técnica do congelamento conferindo maior sensibilidade à técnica. Estes antígenos, quando submetidos a temperaturas de $60^{\circ} \mathrm{C}$ na técnica de cortes parafinados, são desnaturados, restando portanto, os antígenos de natureza polissacarídica (termoestáveis). Este fenômeno faz com que a RIFI-IgM realizada com cortes parafinados do verme sejam positivas apenas quando o paciente está com neuroesquistossomose. A presença de antígenos glicoprotéicos faz com que a RIFI-IgM quando realizada no $L C R$, possa ser positiva mesmo na ausência de comprometimento do sistema nervoso, porque os anticorpos plasmáticos podem passar pela barreira hematoencefálica, mesmo quando íntegra.

Assim, para o diagnóstico da neuroesquistossomose, deve-se utilizar, a técnica de cortes parafinados de verme adulto.

Apesar do eosinófilo ser uma célula com grande representatividade diagnóstica das parasitoses, ficou demonstrado, neste trabalho, que na neuroesquistossomose tal célula tem pouco potencial diagnóstico, pois esteve presente em apenas 7 amostras (36,8\%), variando de 1 a $14 \%$. Este fato já tem sido observado por outros autores ${ }^{11,12}$. Todavia, quando presente no LCR, sempre deve ser levada em consideração. Foi verificado que o eosinófilo em percentagem inferior a $2 \%$ pode estar presente em qualquer processo inflamatório do sistema nervoso ${ }^{13}$. Desta forma, para segurança maior no diagnóstico laboratorial na neuroesquistossomose, esse critério também deve ser observado. Assim, o quadro inflamatório no LCR contrasta com o de outras verminoses do sistema nervoso ${ }^{7,13-16}$, onde o eosinófilo faz parte do processo inflamatório. Sendo a neuroesquistossomose um processo inflamatório crônico decorrente de verminose, era de se esperar uma ocorrência freqüente do eosinófilo no LCR. A possível explicação para a menor presença do eosinófilo na neuroesquistossomose é que o ovo do verme está isolado do tecido nervoso pelo granuloma, o que diminui o efeito da exposição das estruturas antigênicas do ovo ao sistema imune do hospedeiro. Isso dá, provavelmente, uma resposta eosinofílica de menor intensidade ou mesmo ausente no LCR, pois se verifica que o ovo de $S$. mansoni induz uma resposta inflamatória do hospedeiro que resulta na formação do granuloma.

Durante a fase aguda da instalação do ovo no tecido nervoso, ocorre exposição dos antígenos da parede do ovo, que é altamente antigênica. Posteriormente, à medida que a membrana de contenção do ovo vai degenerando, vai ocorrendo li- 
beração de substância intra-ovo que pode também ter poder de estimulação da resposta imune, resultando assim na resposta imune do hospedeiro. Essa produz uma reação inflamatória humoral, por vezes intensa, que acaba por refletir no LCR, modificando suas características. Já na fase crônica, com o granuloma já estabelecido e o ovo isolado do sistema imune, as reações inflamatórias ocorrerão com menor intensidade, ficando a sintomatologia predominante por conta do efeito compre ssivo do granuloma no tecido nervoso ${ }^{17,18}$. Essa evolução da neuroesquistossomose talvez possa provavelmente, justificar as diferenças nas alterações nas amostras de LCR dos diversos pacientes. A célula plasmocitária esteve presente em 8 pacientes $(42,1 \%)$ neste estudo. A célula plasmocitária está associada a doenças crônicas do SN e se correlaciona com a produção intratecal de imunoglubilinas ${ }^{19}$.

Quanto à alteração qualitativa de proteínas, caracterizada pela alteração da relação entre a taxa de proteínas totais e da lgG, verificou-se que no LCR de 14 pacientes (70 \%) houve essa alteração. Ela ocorreu mesmo em amostras que apresentavam as taxas de proteínas totais normais. Outros estudos $^{9,20}$ encontraram IgG aumentada no LCR de pacientes com esquistossomose medular, sendo muito rara a menção a esta proteína. A ocorrência de IgG elevada no soro sangüíneo de pacientes com esquistossomose ${ }^{21,22}$ impede que se possa afirmar que a alteração na proporção da IgG no LCR seja em conseqüência de produção intratecal de globulina gama. Esta alteração pode ser devido ao efeito espelhamento ou seja, apenas passagem passiva da IgG alterada do soro para o LCR. Em estudo de 3 casos de neuroesquistossomose, observou-se que a lgG diminuiu nas amostras de LCR pós tratamento, levantando fortes indícios de síntese intratecal de imunoglobulinas na neuro e squistossomose ${ }^{9}$.

Os neutrófilos estiveram presentes, neste trabaIho em 3 pacientes (15,8\%), sempre em porce $n$ tagem insignificante. A presença de granulócitos neutrófilos não é achado comum na neuroesquistossomose, mas sua presença é citada por alguns autores $^{23}$. O basófilo esteve presente em apenas 1 paciente $(5,3 \%)$. Tais células são observadas no LCR de pacientes com processos agudos diversos do sisteme nervoso como: meningites linfomonocitárias, meningoencefalites e meningomielites, além de outras patologias ${ }^{24}$.
Com relação à taxa de proteínas totais, esta variou de 17 a $280 \mathrm{mg} / \mathrm{dL}$, esteve aumentada em 18 pacientes $(81,8 \%)$. Taxas de proteínas, variando de 31 a 375 mg/dL são citadas na literatura ${ }^{2,9}$. Taxas elevadas, até $900 \mathrm{mg} / \mathrm{dL}$ também são citadas ${ }^{20}$. Provavelmente a associação proteino-citológica ou quadro inflamatório que ocorreu em $77,3 \%$ dos pacientes é resultado da fase inicial ou evolutiva da instalação do ovo no tecido nervoso, quando ocorre o contato íntimo com a meninge; na fase em que o granuloma já está organizado, ou seja, o ovo encontra-se isolado do sistema imune, pode ocorrer dissociação proteino-citológica, caracterizando a síndrome de compressão medular.

$\mathrm{Na}$ tentativa de encontrar alterações que, se associadas, pudessem sugerir uma síndrome para o LCR na neuroesquistossomose, foram feitas associações, entre as alterações apresentadas nos LCRs. Os resultados mais relevantes destas associações, foram o quadro inflamatório que esteve presente em 17 amostras (77,3\%), seguido da associação entre hipercitose e RIFI-IgM positiva que ocorre $u$ em 15 amostras (68,2 \%).

A síndrome do LCR, típica da neuroesquistossomose é descrita por alguns autore ${ }^{25,26}$, caracterizada por hipercitose discreta ou moderada às custas de células linfomonocitárias, com presença de eosinofilos, hiperproteínorraquia discreta ou moderada, e reação positiva para esquistossomose, foi verificada em apenas 4 pacientes. Digna de nota é a constatação de que, em 17 pacientes que a p resentavam quadro inflamatório, $88 \%$ tiveram a RIFI-IgM positiva. Assim, é altamente sugestiva para o diagnóstico da neuroesquistossomose a presença de quadro inflamatório com a RIFI-IgM para esquistossomose positiva. É importante salientar também a possibilidade de LCR normal na neuroesquistossomose, como ocorreu neste trabalho em 3 pacientes (13,7\%). Levando-se isso em conta, não se deve descartar a possibilidade de diagnóstico de neuroesquistossomose mesmo quando o LCR for normal.

Em conclusão: 1. O exame do LCR é um coadjuvante útil para o diagnóstico da esquistossomose raquimedular; 2 . a reação de imunofluorescência indireta foi positiva em $88 \%$ dos pacientes com quando inflamatório; 3 . a alteração qualitativa das proteínas ocorreu em $70 \%$ dos pacientes; 4 . a sínd rome da neuroesquistossomose ocorreu em $20 \%$ dos pacientes; 5 . não foi observada alteração no LCR de $13,7 \%$ dos pacientes. 


\section{REFERÊNCIAS}

1. Urban CA, Piovesan EJ, Almeida SM. Esquistossomose aguda com comprometimento cerebral. Arq Neuropsiquiat 1996;54:677-682.

2. Pe regrino AJP. Meningomielorradiculite por Schistosoma mansoni. Arq Neuropsiquiat 1988;46:49-60.

3. Santos EC, Campos GB, Diniz AC, Leal JC, Rocha MOC. Perfil clínico e critérios diagnósticos da mielorradiculopatia esquistossomótica. Arq Neuropsiquiatr 2001;59:772-777.

4. Razdan S, Vlachiotis JD, Edelstein RA. Schistosomal mielopathy as a cause of neurogenic bladder disfunction. Urology 1997;49:777-780.

5. Ferrari TCA. Spinal cord schistosomiasis: a report of 2 cases and review emphasizing clinical aspects. Medicine 1999;78:176-90.

6. Matas SLA. Reação de imunofluorêscencia indireta e reação imunoenzimática no diagnóstico da neuroesquistossomose mansonica. Tese, Escola Paulista de Medicina; São Paulo1998.

7. Reis JB, Bei A, Reis Filho JB. Líquido cefalorraquiano. São Paulo: Sarvier, 1980.

8. Andrade AS Filho, Reis MG, Souza AL. Neuroesquistossomose mansônica: aspectos clínicos, laboratoriais e terapêuticos. A rq Neuropsiquiat 1996;54:232-237.

9. Haribhai HC. Spinal cord schistosomiasis. Brain 1991;114:709-726.

10. Nash TE, Deelder AM. Comparison of four schistosome excretorysecretory antigens: phenol sulfuric test active peak, cathodic circulating antigen, gut-associated proteoglycan, and circulatin anodic antigen. Am J Trop Med Hyg 1985; 34:236-241.

11. Scully RE. Case re co rds of the Massachusetts general hospital. N Engl J Med dez 1996;335:1906-1913.

12. Scrimgeour EM, Gajdusek DC. Involvement of the central nervous system in Schistosoma mansoni and S. haematobium infection. Brain 1985;108:1023-1038.

13. Reis JB, Pimenta AM, Pupo PP. Cere b rospinal fluid in the diagnosis of brain cysticercosis. Neurologia, Psiquiatria e Neurocirurgia 1964;9:175.

14. Lange $\mathrm{O}$. Sobre as células eosinófilas do líquido cefalorraquiano. Revista de Neurologia e Psiquiatria 1935,1:421.

15. Bosh I, Oehmichen M. Eosinophilic granulocytes in cerebrospinal fluid: analysis of 94 cerebrospinal fluid specimens and review of literature. J Neurol 1978;219:293.

16. Tsai HC, Liu YC, Kunin CM, et al. Eosinophilic meningitis caused by Angiostrongylus cantonensis: report of 17 cases. Am J Med 2001;111: 109-114.

17. Sher A, Coffman RL, Hieny S. Interleukin 5 is required for the blood and tissue eosinophilia but not granuloma formation induced by infection with Schistosoma mansoni. Proc Natl Acad Sci USA 1990;87: 61-65.

18. Wynn TA. Analysis of cytokine mRnA expression during primary granuloma formation induced by eggs of Schistosoma mansoni. J Immunol 2003;151:1430-1440.

19. Prineas JW, Wright RG. Macrophages, lymphocytes, and plasma cells in the perivascular compartment in chronic multiple sclerosis. Lab Invest 1978;38:409-421.

20. Andrade A Filho, Queiroz AC. Meningorradiculite esquistossomótica. Arq Neuropsiquiatr 1991;49:80-82.

21. Brandt CT, Tavares DJS. Esplenose associada a esplenectomia em crianças esquistossomóticas: análise sequencial das imunoglobulinas $\mathrm{G}$, A e M e dos componentes 3 e 4 do sistema complemento. An Fac Med CCS 1993;38:1-14.

22. Coutinho AD, Antunes MTA, Domingues ALC. Estudo da imunidade humoral e celular na doença hepática esquistossomótica. Rev Inst Med Trop 1982;24:282-291.

23. Ferreira MS, Costa-Cruz JM, Gomes MA. Esquistossomose do sistema nervoso central: relato de um caso. A rq Neuropsiquiatr 1990;48: 371-375.

24. Reis JB, Bei A, Mota I, Reis-Filho JB. Os basofilos no líquido cefalorraquiano. Arq Neuropsiquiatr 1973;31:10.

25. Livramento JA, Machado LR, Silva LC. Síndrome do líquido cefalorraquiano na neuroesquistossomose. A rq Neuropsiquiatr 1985;43:372-377.

26. Moreno-Carvalho OA, Nascimento-Carvalho CM, Bacelar ALS, et al. Clinical and cerebrospinal fluid (CSF) profile and CSF criteria for the diagnosis of spinal cord schistosomiasis. Arq Neuropsiquiatr 2003; 61:353-358. 